\title{
EcoBalance 2014: creating benefit through life cycle thinking
}

\author{
Yasushi Kondo • Yasuhiro Fukushima • \\ Shinsuke Murakami
}

Received: 14 February 2014 / Accepted: 19 February 2014 / Published online: 4 March 2014

(C) Springer-Verlag Berlin Heidelberg 2014

We are pleased to inform you that The Institute of Life Cycle Assessment, Japan (ILCAJ) will organize EcoBalance 2014 (the 11th International Conference on EcoBalance) in Tsukuba, Japan from 27 to 30 October 2014.

The conference theme of EcoBalance 2014 is "Creating Benefit through Life Cycle Thinking." We would like to invite a wide range of audience and contributors to share their quests for benefits from life cycle thinking. The participation of and contributions from the industrial sector are particularly encouraged. Realizing that the benefits sought are diverse, contributions from other sectors are also welcome to identify the benefits beyond mere financial considerations in the increasingly globalized supply chain under quickly changing circumstances. The following special sessions will be organized:

- The practical challenge for sustainable industry (M. Motoshita, AIST; M. Nakajima, Kansai University; and M. Finkbeiner, Technical University of Berlin)

- Global food security and corporate practices from life cycle perspectives (K. Hayashi, NARO and K. Matsubae, Tohoku University)
- Sustainability of materials and industries (H. Kakisawa and Y. Matsuno, The University of Tokyo)

Besides the special focus mentioned above, the scope of EcoBalance 2014 includes socio-economic metabolism, industrial symbiosis, sustainable resource management, life cycle management, and socio-economic approaches to sustainability as well as LCA.

Held biennially since 1994, EcoBalance is one of the oldest and most established international conferences on the methodologies and practices of sustainability, based on life cycle thinking. In commemoration of the 20-year history of the EcoBalance conferences, we are organizing, in addition to our regular keynote lectures and sessions, a special session on the prospect of further promoting life cycle thinking in the next 20 years.

For more information, please visit the conference website at http://ilcaj.sntt.or.jp/EcoBalance2014/, or feel free to contact The EcoBalance 2014 secretariat (phone, +81-33503-4681; e-mail, EcoBalance2014@sntt.or.jp).

We look forward to seeing you in Tsukuba, the birthplace of EcoBalance!

\footnotetext{
Y. Kondo $(\bowtie)$

Faculty of Political Science and Economics, Waseda University, 1-6-1 Nishi-waseda, Shinjuku-ku, Tokyo 169-8050, Japan

e-mail: ykondo@waseda.jp

Y. Fukushima

Department of Environmental Engineering, National Cheng Kung

University, No. 1 University Rd, Tainan City 701, Taiwan

S. Murakami

Department of Systems Innovation, Graduate School of Engineering,

The University of Tokyo, 7-3-1 Hongo, Bunkyo-ku,

Tokyo 113-8656, Japan 